\title{
Strength-based mirror effects in item and associative recognition: Evidence for within-list criterion changes
}

\author{
William E. HockLey \\ Wilfrid Laurier University, Waterloo, Ontario, Canada \\ AND \\ Marty W. Niewiadomski \\ University of Toronto, Scarborough, Ontario, Canada
}

\begin{abstract}
Strength-based mirror effects occur when the hit rate is higher and the false alarm rate is lower following strongly encoded study lists than when following more weakly encoded study lists. In Experiments 1A and 1B, strength-based mirror effects were observed in separate tests of single item and associative recognition for random word pairs. In Experiment 2, strength-based mirror effects were again seen when item and associative recognition were tested together. Finally, in Experiments 3 and 4, opposing strength-based mirror effects were observed for item and associative recognition when individual words and word pairs were presented at different rates in the same study lists. Strength-based mirror effects could result from participants' adopting a more conservative decision criterion following strong lists than following weak ones. If this is the case for both item and associative recognition, the present results demonstrate that subjects can adopt different response criteria for different recognition tasks and can alternate between them on a trial-by-trial basis.
\end{abstract}

Glanzer and Adams $(1985,1990)$ showed that the mirror effect is a prevalent feature of recognition memory performance. This effect describes the relationship between hit and false alarm rates across two conditions that differ in terms of their level of discrimination or overall accuracy. More specifically, the hit rate is higher and the false alarm rate is lower in the more accurate condition than in the less accurate condition. In other words, the false alarm rates mirror the order of the hit rates. Two general types of manipulations give rise to the mirror effect. One involves comparing discrimination for different classes or types of stimuli that differ in memorability, and the other involves differentially strengthening one set of study items, relative to another set.

\section{Stimulus-Based Versus Strength-Based Mirror Effects}

A variety of stimulus manipulations give rise to the mirror effect (Glanzer \& Adams, 1985). The prototypical example is word frequency: Low-frequency words are usually associated with a higher hit rate and a lower false alarm rate than are high-frequency words in typical tests of yes-no and forced choice recognition (e.g., Glanzer \& Adams, 1990; but see Criss \& Shiffrin, 2004a, regarding the role of encoding on the generality of the word frequency mirror effect). Another way to produce a mirror pattern involves between-list manipulations of stimulus strength. The hit rate is higher and the false alarm rate is lower for studied items that were presented more often or more slowly than for items that were presented less often or at a faster rate at study (e.g., Cary \& Reder, 2003; Murnane \& Shiffrin, 1991; Stretch \& Wixted, 1998).

Glanzer and Adams's (1985) meta-analysis demonstrating the regularity of stimulus-based mirror effects motivated the development of a number of new theoretical accounts of recognition memory (e.g., Dennis \& Humphreys, 2001; Glanzer \& Adams, 1990; Joordens \& Hockley, 2000; Malmberg, Holden, \& Shiffrin, 2004; McClelland \& Chappell, 1998; Reder et al., 2000; Shiffrin \& Steyvers, 1997). The challenge provided by stimulusbased mirror effects, in signal detection theory (SDT) terms, was to explain why the order of the underlying distributions on the strength-of-evidence axis changes when the different classes of stimuli are old, as compared with when they are new - that is, why the weakest items, when new, become the strongest items, when old. Murdock (2003) has termed this a "leapfrog" effect because the weakest items (low-frequency new items) jump over stronger items (high-frequency new words) to be better remembered at test after a study presentation.

Stretch and Wixted (1998) distinguished between two different SDT-based explanations of the mirror effect. In Type I, or criterion shift, accounts, subjects adopt a more

W. E. Hockley, whockley@wlu.ca 
conservative decision criterion for items in the more memorable condition and a more liberal criterion for items in the less memorable condition, thereby producing a higher false alarm rate in the less memorable condition. Different versions of criterion shift accounts have been proposed for the word frequency stimulus-based mirror effect (e.g., J. Brown, Lewis, \& Monk, 1977; Gillund \& Shiffrin, 1984; Hirshman, 1995) and for between-list strength-based mirror effects (e.g., Cary \& Reder, 2003; Stretch \& Wixted, 1998).

In Type II, or criterion-fixed, accounts, the mirror effect is produced through the appropriate ordering of the underlying distributions on the decision continuum, rather than as a result of a change in the decision criterion. For example, in Glanzer and Adams's (1985, 1990; Glanzer, Adams, Iverson, \& Kim, 1993) attention/likelihood theory, the underlying continuum is a log likelihood ratio decision axis, or the statistical probability of being old. Thus, as applied to the word frequency mirror effect, lowfrequency words are judged to have a higher probability of being old when old and a lower probability of being old when new, as compared with high-frequency words.

Studies of the list strength effect (LSE), the effect of strengthening (or weakening) some list items upon memory for the other items in the list, have provided support for a criterion-based view of strength-based mirror effects. In the LSE procedure, recognition performance for items presented in pure strong, pure weak, or mixed strong/weak lists are compared. Ratcliff, Clark, and Shiffrin (1990) showed that the LSE is typically observed in tests of free recall, but not for item recognition. In all of their recognition experiments, a strength-based mirror pattern is seen in comparisons between the pure strong and the pure weak lists, since the hit rates were higher and the false alarm rates lower for the strong lists. The hit rates were also higher for strong than for weak items in the mixed lists, but the false alarm rates tended to be closer to the average false alarm rate for the pure weak and pure strong lists.

Meta-analyses based on null LSE findings have indicated differences in response bias between the mixed and the pure lists (Chappell \& Humphreys, 1994; Hirshman, 1995). For example, Hirshman compared recognition performance for weak items presented in pure and mixed lists and found that criterion placement shifted upward in the mixed list condition. Hirshman argued that participants estimate the approximate range of familiarity values across the study list items and place their decision criterion at some fixed interval within this range. Thus, participants establish their criterion placement through an assessment of the overall memorability of the items in the study list. Such a strategy for criterion placement would produce strength-based mirror effects in comparisons between pure strong and pure weak lists and would attenuate mirror effects between strong and weak items in comparisons between mixed and pure lists.

Although criterion changes may play an important role in strength-based mirror effects, Stretch and Wixted (1998) have argued that the stimulus-based mirror effect for low versus high word frequency is not accompanied by any change in the decision criterion. Stretch and Wixted differentially strengthened high-frequency words relative to low-frequency words, resulting in a higher hit rate for the high-frequency words, but this manipulation did not affect the typical pattern of the false alarm rates. Moreover, this result was also found when participants were given an unambiguous contextual basis (different background colors) for distinguishing the high- and the low-frequency words at study and test. Stretch and Wixted went on to suggest that "participants may be disinclined to shift the decision criterion on an item-by-item basis during a recognition test even when conditions for doing so are optimal" (p. 1392).

Morrell, Gaitan, and Wixted (2002) have provided further support for this view. They manipulated item strength by presenting items from one semantic category fives times and items from another category only once. This manipulation increased the hit rate for items in the strengthened category, but there was no difference in the false alarm rates between lures from the strong and the weak categories. That is, the within-list manipulation of strength did not produce a mirror effect.

Several recent studies, however, have brought into question the generality of Stretch and Wixted's (1998) and Morrell et al.'s (2002) findings and conclusions. Benjamin and Bawa (2004) and S. Brown and Steyvers (2005) have demonstrated that subjects can adjust their decision criterion in response to changes in the decision environment. In Benjamin and Bawa's study, subjects received a single study phase, followed by two recognition tests that varied in terms of whether the distractors where more or less plausible, as defined by the degree of semantic overlap between the targets and the distractors. The subjects increased their criterion when discrimination became more difficult (i.e., from less plausible to more plausible tests). Interestingly, the subjects did not lower their criterion when the test became easier (i.e., from more to less plausible tests). S. Brown and Steyvers varied the difficulty of a lexical decision task by alternating the nature of the nonwords over blocks of trials. Their results showed slow systematic changes in the decision criteria that took about 14 trials, on average, to accommodate the change in the level of difficulty of the discrimination. Both of these studies demonstrate that subjects do monitor their ongoing discrimination performance and that they are able to adjust their performance in response to changes in task difficulty over time.

Other studies have provided evidence that subjects can alter their decision criterion on a test-by-test basis. Singer, Gagnon, and Richards (2002) and Singer and Wixted (2006) found evidence for trial-by-trial criterion changes in response to different stimulus sets that varied in terms of test delay. In Singer et al.'s study, subjects read five stories and, after a variable delay, read additional stories. Each additional story was followed by a recognition test that included test probes both from the immediately preceding story and from one of the stories read prior to the delay. For delays of $20 \mathrm{~min}, 40 \mathrm{~min}$, and 2 days, the false alarm rate was lower for the short-delay lures than for the longdelay lures. Singer and Wixted extended this result to item recognition of category exemplars. The subjects first studied items from five different categories, and after a delay, five new category lists were presented. After each of the 
delayed lists, the subjects were given a recognition test for the current category and one of the earlier categories. Although no evidence for criterion changes were found for delays of up to $40 \mathrm{~min}$, both yes-no and confidence-rating results indicated that the subjects adopted a more lenient criterion for the delayed, as compared with the immediate, test categories at a delay of 2 days.

Dobbins and Kroll (2005) have demonstrated a mirror effect favoring photographs of well-known scenes, as compared with novel scenes. Furthermore, they showed that speeded recognition and forgetting over a 1-week retention interval reversed the false alarm differences between the two types of scenes. Dobbins and Kroll argued that the mirror effect for known versus unknown scenes is a result of subjects' adopting different decision criteria for the two types of scenes when time permits such a strategy and when the distinctiveness of the stimuli predicts their memorability.

The available evidence does not permit definitive conclusions concerning the general role of criterion changes in stimulus-based and strength-based mirror effects. Nevertheless, it does appear that at least for some stimulus manipulations and under some strengthening conditions, subjects are able to adjust their decision criterion or adopt different decision criteria. Thus, criterion change accounts of mirror effects observed in tests of item recognition cannot be ruled out.

\section{Item Versus Associative Recognition}

Most studies of mirror effects have involved tests of item recognition or tests of memory for the occurrence of individual events. Stimulus-based mirror effects, however, have also been observed for associative recognition, or tests involving memory for relations between individual events (e.g., Greene, 1996; Hockley, 1994; Xu \& Malmberg, 2007). In the typical associative recognition procedure, subjects study randomly paired items and, at test, must distinguish between intact or studied pairs and rearranged pairs. Rearranged pairs consist of two studied items that have not been presented together. Thus, associative recognition decisions cannot be based on memory for the individual items of each pair and, therefore, provide a reasonably pure test of memory for the association between the items that was encoded at study.

Malmberg and $\mathrm{Xu}$ (2007), in their summary of theoretical accounts of associative recognition, distinguished between three general classes of models. One test of these different models concerns the effect of repeating or strengthening some of the pairs in the study phase. All of the models predict that the hit rate will be greater for strong pairs than for weak pairs, but they make different predictions regarding the false alarm rates for strong versus weak rearranged pairs. In within-list comparisons of strong versus weak pairs, Kelley and Wixted (2001) found no difference in the false alarm rates (see also Cleary, Curran, \& Greene, 2001; Xu \& Malmberg, 2007).

In single-process familiarity-based models, it is assumed that recognition is based on a continuous random variable, often referred to as familiarity. For compound cue models of this class (e.g., Gronlund \& Ratcliff, 1989), the items forming a pair are stored together in memory, and familiarity is a function of the similarity between the test probe and the memory representation. Intact pairs, therefore, will have a greater average familiarity than will rearranged pairs, and strengthening pairs will increase the average familiarity of both intact and rearranged pairs, increasing both the hit and the false alarm rates. The latter prediction is inconsistent with the observed results for within-list manipulations of pair strength (Cleary et al., 2001; Kelley \& Wixted, 2001; Xu \& Malmberg, 2007).

Independent cue models are another version of familiaritybased models that assume that the association or relation between the items of the pair is represented in memory separately from the individual items. In the strong version of the independent cue model (e.g., Murdock, 1982), the item information does not systematically affect associative recognition decisions. Intact pairs are stronger than rearranged pairs because only intact pairs are represented in memory. Thus, strengthening intact pairs will increase their familiarity but will have no effect on the familiarity of the rearranged pairs. This prediction is consistent with the null effect of repetition on the false alarm rates for rearranged pairs (Cleary et al., 2001; Kelley \& Wixted, 2001; Xu \& Malmberg, 2007).

Weaker versions of the independent cue model allow item information to influence associative recognition (e.g., Criss \& Shiffrin, 2004b, 2005; Hockley, 1992; Kelley \& Wixted, 2001). Hockley (1992) proposed that item and associative information are combined for intact pairs but that recognition decisions for rearranged pairs are based only on item familiarity. This assumption makes the incorrect prediction that the false alarm rate will be greater for strong rearranged pairs than for weak rearranged pairs. In contrast, Kelley and Wixted suggested that strengthening pairs increases item familiarity but decreases the associative strength of rearranged pairs. If these opposing influences are comparable in magnitude, there will be no effect on false alarm rates. Finally, the independent cue model proposed by Criss and Shiffrin (2004b, 2005), which is an extension of Shiffrin and Steyvers's (1997) REM model, can account for either no change or an increase in the false alarm rate when study pairs are strengthened, depending on whether subjects choose to base their associative recognition decisions only on associative features or on both associative and single-item features.

In contrast to purely familiarity-based models, many current accounts of item recognition assume that responses are based on some combination of familiaritybased decisions and recollection and that the proportion of each type of decision will vary, depending on the study and stimulus conditions (e.g., Joordens \& Hockley, 2000; Malmberg et al., 2004; Reder et al., 2000). Furthermore, many researchers have suggested that recollection, or recall-based processes, may play an even greater role in associative recognition (e.g., Cameron \& Hockley, 2000; Clark \& Hori, 1995; Clark, Hori, \& Callan, 1993; Rotello \& Heit, 2000; Westerman, 2000; Yonelinas, 1997).

In single-process recall-based models (e.g., Diller, Nobel, \& Shiffrin, 2001; Yonelinas, 1997), associative recognition decisions are assumed to be based on using one or both of the members of the test pair to retrieve the 
association formed at study. If the retrieved information matches the test pair, it will be classified as old, and if the retrieved information does not match the test pair, it will be classified as new (i.e., the recall-to-reject strategy). Such models, however, incorrectly predict that strengthening pairs should reduce the false alarm rate because the success of the recall-to-reject strategy should increase with the strength of the studied pairs.

The third class of model of associative recognition, dual process, is represented by the model recently proposed by Xu and Malmberg (2007), who extended Malmberg et al.'s (2004) dual-process REM-based model of item recognition to associative recognition. In the associative recognition model, it is assumed that a familiarity value is first computed. If this value does not exceed a criterion, a new recognition response is made. If the familiarity value does exceed the criterion, the outcome of a recollection process is considered. If recollection is successful and the retrieved details match the probe, the response is old. The response is new if the details do not match the probe. In the event recollection fails, the recognition decision is based on a guess. The bias to respond positively when recollection fails is typically considered to be high, so a pair will usually be called old once it exceeds the familiarity criterion. The level of accuracy of associative recognition performance is determined both by how well pairs are encoded and by the effectiveness of the recall-to-reject strategy. The former largely determines hit rates, whereas the latter has the greatest influence on the false alarm rates.

$\mathrm{Xu}$ and Malmberg (2007) compared the effects of within-list repetition on associative recognition for different types of stimuli. When pairs consisted of familiar types of items (words or faces), false alarms decreased slightly with increased repetition. In contrast, the false alarm rate increased with repetitions for unfamiliar types of stimuli (pseudowords and Chinese characters). The successful fits of their dual-process model to both of these results suggested that associative recognition of familiar stimuli is more likely to be based on recollection than is recognition of unfamiliar stimuli.

As was noted above, comparisons of strong versus weak pairs on the false alarm rates for rearranged pairs in within-list manipulations of pair strength provide an important test of models of associative recognition. In the present study, between-list comparisons of pair strength were examined.

\section{Strength-Based Mirror Effects for Item and Associative Recognition}

The purpose of Experiment 1 was to examine strengthbased mirror effects for item and associative recognition. The failure to find a strength-based mirror pattern in within-list comparisons (Cleary et al., 2001; Kelley \& Wixted, 2001; Xu \& Malmberg, 2007) suggests that one might not find a between-list strength-based mirror effect for associative recognition. Clark and Shiffrin (1992), however, reported two experiments in which word pairs were presented at different rates between lists and subjects performed different memory tasks following each list. Although Clark and Shiffrin analyzed their results only in terms of overall corrected recognition scores, the mean hit and false alarm rates in the fast and slow presentation rate conditions for both item and associative recognition showed a strength-based mirror pattern.

Like the effects of within-list manipulations of strength on false alarm rates, the presence or absence of betweenlist strength-based mirror effects would also have implications for theoretical accounts of associative recognition. As was discussed above, recall-based models would predict a decrease in the false alarm rate for stronger rearranged pairs, whereas different versions of familiaritybased models would predict either no effect or an increase in the false alarm rate. Xu and Malmberg's (2007) dualprocess model could account for no effect or a decrease in the false alarm rate, depending on the role of recollection in the decision process. The finding that in comparison with the null or small effects that have been observed for within-list manipulations, between-list manipulations of strength give rise to the mirror effect would also suggest that the role of criterion changes would need to be considered in any account of associative recognition.

\section{EXPERIMENTS 1A AND 1B}

In Experiments 1A and 1B, one group of subjects studied random pairs of common words that were presented at a fast rate, and another group of subjects studied pairs presented at a slower rate. ${ }^{1}$ The subjects in Experiment 1A were then given a yes/no single item recognition test, whereas the subjects in Experiment 1B were given an intact/rearranged associative recognition test.

\section{Method}

Subjects. Sixty-six students participated in Experiment 1A, and a further 66 in Experiment 1B. The subjects in these and the following experiments were students of introductory psychology, who participated for course credit.

Stimuli and Apparatus. All words were selected from a pool of 500 words taken from the Toronto Word Pool (Friendly, Franklin, Hoffman, \& Rubin, 1982). The words consisted of common twosyllable nouns of not more than eight letters. List generation, display, and response recording were controlled by IBM-compatible laboratory computers equipped with 17 -in. flat-screen monitors. The subjects used the "z" and "/" keys to respond new and old, respectively.

Procedure. Each subject in each experiment completed five study-test cycles. The study lists consisted of 36 critical random pairs of words, plus two additional pairs at the beginning and end of the list to absorb primacy and recency effects. For half the subjects in each experiment, the study list was presented at a $1-\mathrm{sec}$ rate per pair, and for the other half of the subjects, the rate was $4 \mathrm{sec}$ per pair. The blank interstimulus interval was $1 \mathrm{sec}$. Depending on the test condition, the subjects were instructed to study each pair so that they would either remember the individual words or remember which words had been presented together at study.

The test lists in Experiment 1A consisted of 20 single old study words (10 left-hand pair members and 10 right-hand pair members, taken from different study pairs) and 20 new words presented in a random order. In Experiment 1B, the test lists consisted of 12 intact study pairs and 12 rearranged study pairs, presented in random order. The rearranged pairs preserved the left-right order of the individual words with respect to their positions in the study pairs. The test list was subject-paced, with a 1-sec blank interval between a response and the subsequent test. In each experiment, the subjects were instructed to respond both as accurately and as quickly as possible. 
Table 1

Mean Estimates of Sensitivity $\left(d^{\prime}\right)$ and Criterion Placement $(C)$ and Standard Errors of the Means ( $S E s)$ for the Separate Tests of Item and Associative (Pair) Recognition in the Fast and Slow Presentation Conditions in Experiments $1 \mathrm{~A}$ and $1 \mathrm{~B}$

\begin{tabular}{|c|c|c|c|c|c|c|c|c|}
\hline \multirow[b]{3}{*}{ Test } & \multicolumn{4}{|c|}{ Fast Presentation Rate } & \multicolumn{4}{|c|}{ Slow Presentation Rate } \\
\hline & \multicolumn{2}{|c|}{$d^{\prime}$} & \multicolumn{2}{|c|}{$C$} & \multicolumn{2}{|c|}{$d^{\prime}$} & \multicolumn{2}{|c|}{$C$} \\
\hline & $M$ & $S E$ & $M$ & $S E$ & $M$ & $S E$ & $M$ & $S E$ \\
\hline Item & 1.21 & 0.07 & .05 & .05 & 1.84 & 0.10 & .07 & .01 \\
\hline Pair & 0.91 & 0.14 & .12 & .05 & 2.24 & 0.20 & .22 & .04 \\
\hline
\end{tabular}

\section{Results and Discussion}

Mean estimates of $d^{\prime}$, the signal detection estimate of discrimination, and $C$, the corresponding estimate of criterion placement, are given in Table 1 for each presentation rate condition for each experiment. ${ }^{2}$ These estimates were calculated in order to provide a summary measure of discrimination performance and to evaluate the overall effectiveness of the strength manipulation. The single-point estimates of both $d^{\prime}$ and $C$ should be treated with some caution, however, because they were calculated on the basis of an equal variance detection model, which is not usually appropriate for yes-no recognition. This problem may also be greater for estimates of $C$ than for those of $d^{\prime}$ if the changes in criterion placement are more subtle than the effects of the strength manipulations on $d^{\prime}$. Although we will report the estimates and analyses of $C$ for the sake of completeness, we believe that changes in false alarm rates are more diagnostic of criterion shifts than are the estimates of $C$.

The difference in presentation rate was successful in influencing recognition performance, since $d^{\prime}$ was significantly greater in the slow than in the fast presentation condition for item recognition $[t(64)=5.161, p<.001]$ and associative recognition $[t(64)=5.407, p<.001]$. Estimates of criterion placement were also somewhat more conservative in the slow than in the fast presentation condition, but the differences were not statistically reliable for either item recognition $[t(64)=0.417, p=.678]$ or associative recognition $[t(64)=1.461, p=.149]$.

Mean hit and false alarm rates for item and associative recognition are shown in Table 2. A mirror pattern is evident, since the hit rates are higher and the false alarm rates lower in the slow than in the fast presentation condition. A 2 (fast or slow presentation rate) $\times 2$ (old or new test probe) mixed factor ANOVA based on the proportion of positive responses for item recognition revealed a significant main effect of test probe $\left[F(1,64)=846.4, M S_{\mathrm{e}}=\right.$ $\left.0.010, p<.001, \eta^{2}=.930\right],{ }^{3}$ whereas the main effect of presentation rate approached significance $[F(1,64)=$ $\left.3.345, M S_{\mathrm{e}}=0.017, p=.072, \eta^{2}=.050\right]$. More important, the interaction between these variables that evidences the mirror effect was reliable $\left[F(1,64)=19.76, M S_{\mathrm{e}}=\right.$ $\left.0.010, p<.001, \eta^{2}=.236\right]$. The hit rate was higher in the slow than in the fast presentation condition, but this difference was not statistically reliable $[t(64)=1.413, p=$ .16]. The false alarm rate was almost twice as great in the fast presentation condition as in the slow one, and this difference was significant $[t(64)=3.932, p<.001]$.
The corresponding ANOVA for associative recognition revealed that the main effect of test probe was significant $\left[F(1,64)=266.1, M S_{\mathrm{e}}=0.029, p<.001, \eta^{2}=\right.$ .807], whereas the main effect of presentation rate was not $[F(1,64)<1]$. The interaction between these factors, however, was again significant $\left[F(1,64)=33.34, M S_{\mathrm{e}}=\right.$ $\left.0.029, p<.001, \eta^{2}=.346\right]$. The hit rate was significantly higher $[t(64)=3.988, p<.001]$, and the false alarm rate was reliably lower $[t(64)=5.345, p<.001]$, in the slow presentation condition than in the fast one.

Experiment 1A replicated the strength-based mirror pattern for item recognition. A straightforward account of this effect is that subjects adopt a more liberal decision criterion following rapidly presented lists and a more conservative criterion after more slowly presented lists because they appreciate that recognition memory will be better for lists presented at a slower rate. The criterion change account provides a logical reason as to why the false alarm rates differed between the fast and the slow presentation conditions when the new tests were based on items that were nominally the same.

Experiment 1B provides a robust demonstration of a strength-based mirror effect for associative recognition. The decrease in false alarm rates with increased strength is consistent with the predictions of single-process recallbased models (e.g., Yonelinas, 1997) and Xu and Malmberg's (2007) dual-process model if it is assumed that recollection plays a greater role when the strength of the pairs is greater. The decrease in false alarm rate is inconsistent with single-process familiarity-based models that predict either no effect or an increase in the false alarm rate with increases in pair strength. A challenge for all models of associative recognition is to account for both the betweenlist mirror effect found in Experiment 1B and the null or much more modest effects of within-list manipulations of strength on false alarm rates (Cleary et al., 2001; Kelley \& Wixted, 2001; Xu \& Malmberg, 2007). One way to address this challenge is to assume that criterion changes play a greater role in between-list than in within-list manipulations of strength. The following experiments were designed to further examine the possible role of criterion changes in strength-based mirror effects.

\section{EXPERIMENT 2}

Experiments 1A and 1B provided separate demonstrations of strength-based mirror effects for item and associative recognition. The purpose of Experiment 2 was to see

Table 2

Mean Hit (HR) and False Alarm (FAR) Rates and Standard Errors of the Means (SEs) for the Separate Tests of Item and Associative (Pair) Recognition in the Fast and Slow Presentation Conditions in Experiments $1 \mathrm{~A}$ and 1B

\begin{tabular}{|c|c|c|c|c|c|c|c|c|}
\hline \multirow[b]{3}{*}{ Test } & \multicolumn{4}{|c|}{ Fast Presentation Rate } & \multicolumn{4}{|c|}{ Slow Presentation Rate } \\
\hline & \multicolumn{2}{|c|}{ HR } & \multicolumn{2}{|c|}{ FAR } & \multicolumn{2}{|c|}{ HR } & \multicolumn{2}{|c|}{ FAR } \\
\hline & $M$ & $S E$ & $M$ & $S E$ & $M$ & $S E$ & $M$ & $S E$ \\
\hline Item & .70 & .02 & .27 & .02 & .74 & .02 & .15 & .02 \\
\hline Pair & .62 & .03 & .31 & .03 & .78 & .03 & .13 & .02 \\
\hline
\end{tabular}


whether both mirror effects could be observed when both types of recognition tests were performed in the same test list. Thus, in Experiment 2, the subjects studied random pairs of words presented at either a slow or a fast rate, and then their recognition memory for both item and associative information was tested after each study list.

\section{Method}

Subjects. There were 26 subjects in the fast presentation list condition, and 33 in the slow presentation condition.

Apparatus and Stimuli. The apparatus and word pool were the same as those used in Experiments 1A and 1B.

Procedure. The subjects completed five study-test cycles. The procedure was the same as that used in Experiments $1 \mathrm{~A}$ and 1B, except for the construction of the test lists following each study list of 40 word pairs. The test lists consisted of 8 words taken from 8 different study pairs (four left-pair members and four right-pair members), eight new words, 8 intact study pairs, and 8 rearranged study pairs, presented in a different random order for each list and subject. The old single words, intact pairs, and rearranged pairs were all derived from different study pairs (the 36 critical study pairs). The subjects were instructed to study each pair so that they would be able to remember both the individual words and which words had been presented together. At test, The subjects were encouraged to make each recognition decision as accurately and as quickly as possible, but the emphasis was placed on accuracy.

\section{Results and Discussion}

The mean $d^{\prime}$ and $C$ estimates for each type of recognition test in each presentation rate condition are given in Table 3. A 2 (item vs. pair recognition test) $\times 2$ (fast vs. slow presentation rate) mixed factor ANOVA based on estimates of $d^{\prime}$ showed that overall, discrimination was greater for item recognition than for associative recognition $\left[F(1,57)=8.97, M S_{\mathrm{e}}=0.374, p=.004, \eta^{2}=.136\right]$ and that discrimination was greater in the slow than in the fast presentation rate condition $\left[F(1,57)=16.99, M S_{\mathrm{e}}=\right.$ $\left.1.19, p<.001, \eta^{2}=.230\right]$. The interaction between type of test and presentation rate did not approach significance $(F<1)$. The same analysis based on the estimates of $C$ revealed that criterion placement was more conservative for item than for associative recognition decisions $[F(1,57)=$ 9.61, $\left.M S_{\mathrm{e}}=0.151, p=.003, \eta^{2}=.144\right]$ and was also more conservative in the slow rate condition than in the fast rate condition $\left[F(1,57)=4.397, M S_{\mathrm{e}}=0.198, p=\right.$ $\left..040, \eta^{2}=.072\right]$. The interaction between these variables did not approach significance $(F<1)$.

The mean hit and false alarm rates for item and associative recognition in each presentation rate condition are shown in Table 4. A 2 (item vs. associative recognition test) $\times 2$ (fast vs. slow presentation rate) $\times 2$ (old vs.

Table 3

Mean Estimates of Sensitivity $\left(d^{\prime}\right)$ and Criterion Placement $(C)$ and Standard Errors of the Means ( $S E s$ ) for the Separate Tests of Item and Associative (Pair) Recognition in the Fast and Slow Presentation Conditions in Experiment 2

\begin{tabular}{|c|c|c|c|c|c|c|c|c|}
\hline \multirow[b]{3}{*}{ Test } & \multicolumn{4}{|c|}{ Fast Presentation Rate } & \multicolumn{4}{|c|}{ Slow Presentation Rate } \\
\hline & \multicolumn{2}{|c|}{$d^{\prime}$} & \multicolumn{2}{|c|}{$C$} & \multicolumn{2}{|c|}{$d^{\prime}$} & \multicolumn{2}{|c|}{$C$} \\
\hline & $M$ & $\overline{S E}$ & $M$ & $S E$ & $M$ & $S E$ & $M$ & $S E$ \\
\hline Item & 1.21 & 0.11 & .04 & .07 & 1.93 & 0.15 & .17 & .06 \\
\hline Pair & 0.76 & 0.14 & -.22 & .09 & 1.70 & 0.21 & -.02 & .08 \\
\hline
\end{tabular}

Table 4

Mean Hit (HR) and False Alarm (FAR) Rates and Standard Errors of the Means (SEs) for the Separate Tests of Item and Associative (Pair) Recognition in the Fast and Slow Presentation Conditions in Experiment 2

\begin{tabular}{|c|c|c|c|c|c|c|c|c|}
\hline \multirow[b]{3}{*}{ Test } & \multicolumn{4}{|c|}{ Fast Presentation Rate } & \multicolumn{4}{|c|}{ Slow Presentation Rate } \\
\hline & \multicolumn{2}{|c|}{ HR } & \multicolumn{2}{|c|}{ FAR } & \multicolumn{2}{|c|}{ HR } & \multicolumn{2}{|c|}{ FAR } \\
\hline & $M$ & $S E$ & $M$ & $S E$ & $M$ & $S E$ & $M$ & $S E$ \\
\hline Item & .70 & .03 & .28 & .03 & .77 & .02 & .17 & .02 \\
\hline Pair & .71 & .03 & .45 & .05 & .78 & .03 & .25 & .04 \\
\hline
\end{tabular}

new probe) mixed factor ANOVA based on the proportions of positive responses revealed significant main effects of test probe $\left[F(1,57)=252.2, M S_{\mathrm{e}}=0.047, p<\right.$ $\left..001, \eta^{2}=.816\right]$ and type of test $\left[F(1,57)=9.288, M S_{\mathrm{e}}=\right.$ $\left.0.028, p=.003, \eta^{2}=.140\right]$. The main effect of presentation rate $\left[F(1,57)=2.882, M S_{\mathrm{e}}=0.033, p=.095, \eta^{2}=\right.$ $.048]$ was not reliable. Two interactions were significant. The hit rates for item and associative recognition were comparable, but the false alarm rates were greater for associative recognition, producing an interaction between type of test and test probe $\left[F(1,57)=12.93, M S_{\mathrm{e}}=0.015\right.$, $\left.p=.001, \eta^{2}=.185\right]$. More important, the interaction between presentation rate and test probe that provides a measure of the mirror effect was reliable $[F(1,57)=16.199$, $\left.M S_{\mathrm{e}}=0.047, p<.001, \eta^{2}=.221\right]$. The mirror effect for both item and associative recognition was seen in terms of higher hit rates $[t(57)=2.03, p=.047$, and $t(57)=$ $2.33, p=.024$, respectively] and lower false alarm rates $[t(57)=3.19, p=.002$, and $t(57)=3.17, p=.002$, respectively] in the slow presentation condition.

Experiment 2 demonstrated that strength-based mirror effects can be observed for both item and associative recognition when they are tested together. This result raises some interesting questions regarding the nature of possible criterion changes within and between lists. If the strengthbased mirror effects for both item and associative recognition are based on criterion changes, and if we assume that the nature of the criteria are different for item and associative recognition, the results of Experiment 2 suggest that subjects can alter their decision criterion on a trial-by-trial (or probe-by-probe) basis as they alternate between the two types of recognition decisions. Of course, the assumption that the criteria for item and associative recognition decisions are different need not be the case. Experiment 3 was designed to provide a situation in which the criteria for these two types of decisions would necessarily have to be different if both item and associative strength-based mirror effects are due to criterion changes.

\section{EXPERIMENT 3}

The subjects in Experiment 3 studied lists consisting of both single items and word pairs. For half the lists, words were presented at a slow rate, and pairs were presented at a fast rate; the reverse was true for the other half of the lists. Words and pairs were presented in a blocked fashion in each list in order to reduce rehearsal borrowing between fast and slow presentations (cf. Yonelinas, Hockley, \& Murdock, 
1992; Ratcliff et al., 1990). Both item and associative recognition were tested following each study list. If strengthbased mirror effects are due to criterion changes for both item and associative recognition, the subjects in Experiment 3 would have to set different and opposing decision criteria for their item and associative recognition decisions in order to produce mirror effects for each type of test.

\section{Method}

Subjects. A total of 32 students participated.

Apparatus and Stimuli. The apparatus and word pool were the same as used in the earlier experiments.

Procedure. All the subjects completed four study-test cycles. Each study list consisted of 30 single words and 30 randomly paired words. These stimuli were blocked in the following order: 5 single words (buffer items), 10 single words, 15 word pairs, 10 single words, 15 word pairs, and 5 single words (buffers). In half the lists, the single words were presented for $1 \mathrm{sec}$, and the word pairs for $4 \mathrm{sec}$ (fast-item/slow-pair lists). In the other half of the lists, the single words were shown for $3 \mathrm{sec}$, and the word pairs were shown for $1 \mathrm{sec}$ (slow-item/fast-pair lists). There was always a 1-sec blank interval between presentations. The four initial orders of the fast $(\mathrm{F})$ and slow (S) presentation rates across the list blocks (F-S-F-S, SF-S-F, F-S-S-F, and S-F-F-S) were counterbalanced across subjects. Within-subjects, the presentation rate for item and associative presentations alternated over the four study-test cycles (i.e., F-S-FS, S-F-S-F, F-S-F-S, and S-F-S-F). Thus, each subject received alternating lists of slow-items/fast-pairs and fast-items/slow-pairs.

The test lists consisted of 40 trials: 10 old single items, 10 new single items, 10 intact pairs, and 10 rearranged pairs, presented in a freshly randomized order for each list. An equal number of test items were taken from each critical study list block (excluding the buffer presentations).

\section{Results and Discussion}

Mean estimates of $d^{\prime}$ and $C$ for each recognition test at each presentation rate are shown in Table 5. A 2 (item vs. associative recognition) $\times 2$ (fast vs. slow presentation rate) within-subjects ANOVA based on $d^{\prime}$ estimates showed that overall, discrimination was greater for item recognition than for associative recognition $[F(1,31)=58.06$, $\left.M S_{\mathrm{e}}=0.039, p<.001, \eta^{2}=.652\right]$ and was greater in the slow than in the fast presentation rate condition $[F(1,31)=$ $\left.6.106, M S_{\mathrm{e}}=0.271, p<.019, \eta^{2}=.165\right]$. These variables did not interact $(F<1)$. The corresponding analysis of the estimates of criterion placement showed that the main effects of type of recognition test $\left[F(1,31)=1.683, M S_{\mathrm{e}}=\right.$ $\left.0.206, p=.204, \eta^{2}=.136\right]$ and presentation rate $(F<1)$ and their interaction $(F<1)$ were not significant.

Mean hit and false alarm rates for each recognition test at each presentation rate are shown in Table 6. A 2 (old

Table 5

Mean Estimates of Sensitivity $\left(d^{\prime}\right)$ and Criterion Placement $(C)$ and Standard Errors of the Means (SEs) for the Separate Tests of Item and Associative (Pair) Recognition In the Fast and Slow Presentation Conditions in Experiment 3

\begin{tabular}{|c|c|c|c|c|c|c|c|c|}
\hline \multirow[b]{3}{*}{ Test } & \multicolumn{4}{|c|}{ Fast Presentation Rate } & \multicolumn{4}{|c|}{ Slow Presentation Rate } \\
\hline & \multicolumn{2}{|c|}{$d^{\prime}$} & \multicolumn{2}{|c|}{$C$} & \multicolumn{2}{|c|}{$d^{\prime}$} & \multicolumn{2}{|c|}{$C$} \\
\hline & $M$ & $S E$ & $M$ & $S E$ & $M$ & $\overline{S E}$ & $M$ & $S E$ \\
\hline Item & 1.29 & .11 & .10 & .08 & 1.47 & .15 & .09 & .07 \\
\hline Pair & 0.40 & .10 & .19 & .07 & 0.68 & .10 & .21 & .08 \\
\hline
\end{tabular}

Table 6

Mean Hit (HR) and False Alarm (FAR) Rates and Standard Errors of the Means (SEs) for the Separate Tests of Item and Associative (Pair) Recognition in the Fast and Slow Presentation Conditions in Experiment 3

\begin{tabular}{|c|c|c|c|c|c|c|c|c|}
\hline \multirow[b]{3}{*}{ Test } & \multicolumn{4}{|c|}{ Fast Presentation Rate } & \multicolumn{4}{|c|}{ Slow Presentation Rate } \\
\hline & \multicolumn{2}{|c|}{$\mathrm{HR}$} & \multicolumn{2}{|c|}{ FAR } & \multicolumn{2}{|c|}{ HR } & \multicolumn{2}{|c|}{ FAR } \\
\hline & $M$ & $S E$ & $M$ & $\overline{S E}$ & $M$ & $\overline{S E}$ & $M$ & $\overline{S E}$ \\
\hline Item & .69 & .03 & .26 & .03 & .72 & .03 & .24 & .03 \\
\hline Pair & .51 & .03 & .36 & .03 & .55 & .02 & .32 & .04 \\
\hline
\end{tabular}

vs. new test probes) $\times 2$ (item vs. associative recognition) $\times 2$ (fast vs. slow presentation rate) within-subjects ANOVA revealed only a main effect of old versus new discrimination $\left[F(1,31)=177.2, M S_{\mathrm{e}}=0.037, p<.001\right.$, $\left.\eta^{2}=.851\right]$, although the difference between item and associative recognition approached significance $[F(1,31)=$ $\left.3.021, M S_{\mathrm{e}}=0.047, p=.092, \eta^{2}=.089\right]$. The interaction between test probe and type of recognition test was significant $\left[F(1,31)=71.29, M S_{\mathrm{e}}=0.016, p<.001\right.$, $\left.\eta^{2}=.697\right]$, showing that the difference in hit rates was greater than the difference in false alarm rates for item recognition. More important, the critical interaction between test probe and presentation rate that provides a test of the mirror effect was the only other significant interaction $\left[F(1,31)=5.327, M S_{\mathrm{e}}=0.014, p=.028, \eta^{2}=\right.$ .147]. Although the direction of the differences between the hit and the false alarm rates conformed to the mirror effect pattern, neither the differences in hit rates for item and associative recognition $[t(31)=1.059, p=.298$, and $t(31)=1.324, p=.195]$ nor the differences in false alarm rates $[t(31)=0.824, p=.416$, and $t(31)=1.641, p=$ .111] were statistically reliable.

Both item and associative recognition showed a strengthbased mirror effect pattern, even though the strengths of item and associative information were manipulated in an opposing fashion at study. The magnitude of the differences for both hit and false alarm rates for item and associative recognition, however, were much smaller than the effects observed in Experiments 1 and 2. In addition, associative recognition performance was much poorer than in the previous experiments. It appears that the subjects may have had some difficulty in dealing with the alternating presentation rates that occurred both within and between lists. The subjects may also have emphasized the encoding of item over associative information in dealing with this relatively complex task. Thus, we deemed it advisable to replicate the results of Experiment 3 with a less demanding task before considering the implications of these results.

\section{EXPERIMENT 4}

In this last experiment, the subjects studied lists of single items and random word pairs. For one group of subjects, single words were presented at a fast rate, and word pairs were presented at a slow rate in each list. For a second group of subjects, the opposite was the case. Thus, each subject experienced only one presentation rate for each type of stimulus. The stimulus and presentation rate 
manipulations were also blocked by list half so that the subjects would not have to alternate their encoding of item and associative information more than once in each study list. Borrowing from Stretch and Wixted (1998), single items were presented in red at study and test, whereas word pairs were shown in green. This was done to highlight the two types of information and the two types of recognition tests for the subjects.

\section{Method}

Subjects. There were 32 subjects in each of the two presentation rate conditions.

Apparatus and Stimuli. The apparatus and word pool were the same as those used in the earlier experiments.

Procedure. The subjects completed four study-test cycles. The study list consisted of 25 single words presented in red in the first half of the list and 35 word pairs shown in green in the second half of the list. ${ }^{4}$ The first five single words and last five word pairs served as primacy and recency buffers and were not tested. For one group of subjects, the single words were presented at a 1-sec presentation rate, and the word pairs were shown at a 4-sec rate. The presentation rates were $3 \mathrm{sec}$ for single words and $1 \mathrm{sec}$ for pairs for the second group. The blank interstimulus interval was always $1 \mathrm{sec}$.

The test list consisted of 10 single old words, 10 single new words, 10 intact pairs, and 10 rearranged pairs. The old single words, intact pairs, and rearranged pairs were derived from separate study pairs in the same manner as that in Experiment 3. Single-item tests were presented in red, and pair tests were presented in green. The order of tests was freshly randomized for each test list and subject.

\section{Results and Discussion}

The mean estimates of $d^{\prime}$ and $C$ for each type of recognition test and presentation condition are given in Table 7 . A 2 (fast-item/slow-pair group vs. slow-item/fast-pair group) $\times 2$ (item vs. associative recognition test) ANOVA based on the $d^{\prime}$ estimates showed that discrimination was greater for item than for associative recognition $\left[F(1,62)=37.572, M S_{\mathrm{e}}=0.243, p<.001, \eta^{2}=.377\right]$. The main effect of group was not significant $[F(1,62)=$ $\left.0.503, M S_{\mathrm{e}}=0.627, p=.481, \eta^{2}=.008\right]$, but the interaction between the group and the test variables was reliable $\left[F(1,62)=55.965, M S_{\mathrm{e}}=0.243, p<.001, \eta^{2}=.474\right]$. Discrimination was greater in the slow presentation rate condition for both item recognition $[t(62)=4.861, p<$ $.001]$ and associative recognition $[t(62)=3.167, p=$ .002]. The corresponding ANOVA based on estimates of $C$ indicated that criterion placement was more conservative for item than for associative recognition $[F(1,62)=$ 14.56, $\left.M S_{\mathrm{e}}=0.087, p<.001, \eta^{2}=.190\right]$. Estimates of $C$ were somewhat more conservative in the slow than in the fast presentation rate condition, but this difference was not

Table 7

Mean Estimates of Sensitivity $\left(d^{\prime}\right)$ and Criterion Placement $(C)$ and Standard Errors of the Means ( $S E s)$ for the Separate Tests of Item and Associative (Pair) Recognition in the Fast and Slow Presentation Conditions in Experiment 4

\begin{tabular}{|c|c|c|c|c|c|c|c|c|}
\hline \multirow[b]{3}{*}{ Test } & \multicolumn{4}{|c|}{ Fast Presentation Rate } & \multicolumn{4}{|c|}{ Slow Presentation Rate } \\
\hline & \multicolumn{2}{|c|}{$d^{\prime}$} & \multicolumn{2}{|c|}{$C$} & \multicolumn{2}{|c|}{$d^{\prime}$} & \multicolumn{2}{|c|}{$C$} \\
\hline & $M$ & $S E$ & $M$ & $S E$ & $M$ & $S E$ & $M$ & $S E$ \\
\hline Item & 1.24 & 0.09 & .08 & .05 & 1.99 & 0.13 & .14 & .06 \\
\hline Pair & 0.81 & 0.08 & -.14 & .04 & 1.36 & 0.16 & -.03 & .05 \\
\hline
\end{tabular}

Table 8

Mean Hit (HR) and False Alarm (FAR) Rates and Standard Errors of the Means (SEs) for the Separate Tests of Item and Associative (Pair) Recognition in the Fast and Slow Presentation Conditions in Experiment 4

\begin{tabular}{|c|c|c|c|c|c|c|c|c|}
\hline \multirow[b]{3}{*}{ Test } & \multicolumn{4}{|c|}{ Fast Presentation Rate } & \multicolumn{4}{|c|}{ Slow Presentation Rate } \\
\hline & \multicolumn{2}{|c|}{ HR } & \multicolumn{2}{|c|}{ FAR } & \multicolumn{2}{|c|}{ HR } & \multicolumn{2}{|c|}{ FAR } \\
\hline & $M$ & $S E$ & $M$ & $S E$ & $M$ & $S E$ & $M$ & $S E$ \\
\hline Item & .70 & .02 & .26 & .02 & .79 & .02 & .16 & .02 \\
\hline Pair & .70 & .02 & .41 & .03 & .75 & .02 & .29 & .03 \\
\hline
\end{tabular}

reliable $(F<1)$. The interaction between these variables also was not significant $\left[F(1,62)=2.478, M S_{\mathrm{e}}=0.087\right.$, $\left.p=.121, \eta^{2}=.038\right]$.

The mean hit and false alarm rates for each type of recognition test and presentation rate condition are given in Table 8. They show a mirror pattern for both item and associative recognition, since the hit rates are higher and the false alarm rates lower in the slow than in the fast presentation conditions. A 2 (group) $\times 2$ (item vs. associative recognition test) $\times 2$ (old vs. new test probe) mixed factor ANOVA revealed significant main effects of type of recognition test $\left[F(1,62)=13.05, M S_{\mathrm{e}}=0.017, p=\right.$ $\left..001, \eta^{2}=.174\right]$ and test probe $\left[F(1,62)=495.6, M S_{\mathrm{e}}=\right.$ $\left.0.027, p<.001, \eta^{2}=.889\right]$. The main effect of group and the group $\times$ probe interaction were not reliable $\left(F_{\mathrm{s}}<1\right)$. The main effects of test and test probe were qualified by two interactions. The test $\times$ probe interaction $[F(1,62)=$ $\left.43.83, M S_{\mathrm{e}}=0.009, p<.001, \eta^{2}=.414\right]$ showed that the false alarm rate was greater for associative than for item recognition. More important, the test $\times$ probe $\times$ group interaction was significant $\left[F(1,62)=51.40, M S_{\mathrm{e}}=0.009\right.$, $\left.p<.001, \eta^{2}=.453\right]$. This interaction reflects the mirror effects for item and associative recognition for the opposing presentation rates. The effect of presentation rate on item recognition was reliable for both hit rate $[t(62)=$ $3.048, p=.003]$ and false alarm rate $[t(62)=3.177$, $p=.002]$. For associative recognition, the difference in hit rates was in the appropriate direction but was not reliable $[t(62)=1.572, p=.121]$, but the difference in false alarm rates was significant $[t(62)=2.597, p=.012]$.

As compared with that in Experiment 3, the simpler design in Experiment 4 was successful in improving recognition performance, particularly for associative recognition. More interesting, Experiment 4 demonstrated, in a more impressive fashion, the finding of opposing strength-based mirror effects for both item and associative recognition. If the strength-based mirror effects for both item and associative recognition are due to criterion changes, the subjects in Experiments 3 and 4 need to have alternated their decision criteria in opposite directions between the two types of recognition tests.

\section{GENERAL DISCUSSION}

The present study provides a demonstration of the strength-based mirror effect for item recognition, replicating prior findings (e.g., Cary \& Reder, 2003; Ratcliff et al., 1990; Stretch \& Wixted, 1998). A simple and par- 
simonious interpretation of this effect is that subjects adopt a more conservative decision criterion following strongly encoded study lists and a more liberal criterion following more weakly encoded lists. This change in criteria provides a straightforward account of why the false alarm rates for the identical lures would differ between the strong and the weak list conditions.

In addition, the present study demonstrated that betweenlist manipulations of strength also produce a mirror effect for associative recognition, replicating and confirming the pattern seen in the results of Clark and Shiffrin (1992). As was noted in the discussion of Experiment 1, the decrease in false alarm rates with increased strength is inconsistent with single-process familiarity-based models that predict either no effect or an increase in the false alarm rate with increases in pair strength. The decrease in false alarm rate is consistent with the predictions of single-process recallbased models (e.g., Yonelinas, 1997), but these models cannot also account for the failure to find such an effect in within-list manipulations of pair strength (Cleary et al., 2001; Kelley \& Wixted, 2001; Xu \& Malmberg, 2007). This result is also consistent with Xu and Malmberg's dual-process model of associative recognition, given the reasonable assumption that recollection has a greater influence when pair strength is greater. This account, however, must also provide an explanation of why such effects are absent or attenuated in within-list manipulations of pair strength.

It seems likely that metamemory strategies play a role in how the effects of pair strength on associative recognition performance are manifested in within-list and between-list manipulations. Since both familiarity-based models and Xu and Malmberg's (2007) dual-process model include a decision criterion, one can presumably account for between-list strength-based mirror effects in these models in the same manner as can be done for item recognition by assuming that subjects adopt a more liberal criterion following weakly encoded study lists than for strongly encoded lists. Subjects may be less likely to adopt such a strategy when pair strength is manipulated within lists, perhaps because, as Stretch and Wixted (1998) have argued for item recognition, it is usually easier or more efficient to adopt a common decision strategy on a list-wide basis, rather than on a trial-by-trial basis.

In addition to demonstrating strength-based mirror effects for item and associative recognition, the results of Experiments 3 and 4 further showed that these two mirror effects can occur even when the strength of item and associative information is manipulated in opposite directions across the study lists. If both of these mirror effects are due to criterion changes, it follows that the subjects were able to adopt one response criterion for item recognition decisions and a different standard for associative recognition decisions and to alternate between them, as necessary, on a trial-by-trial basis. However, in comparison with the mirror effects observed in Experiment 4, the much more modest effects seen in Experiment 3 also indicate that there are limits to subjects' ability or willingness to continually change their decision criterion.

\section{Conclusion}

The present study demonstrates strength-based mirror effects for both item and associative information when they are tested either separately or together. Moreover, both mirror effects can still occur when the strength of the item and associative information are manipulated in opposite directions in the same test lists. These results are consistent with the view that both types of recognition decisions are based, at least in part, on an assessment of the evidence for each type of decision and that the decision criterion used in this assessment is more conservative following strongly encoded lists and more liberal following more weakly encoded lists. If this view is correct, the present results also demonstrate that subjects are able to adopt different decision criteria for the two recognition tasks and to alternate between them on a trial-by-trial basis.

\section{AUTHOR NOTE}

This research was supported by a discovery grant from the Natural Sciences and Engineering Research Council of Canada, held by the first author. We thank Amy Criss, Simon Dennis, Ken Malmberg, and Lynne Reder for their very constructive reviews. Correspondence should be addressed to W. E. Hockley, Department of Psychology, Wilfrid Laurier University, Waterloo, ON, N2L 3C5 Canada (e-mail: whockley @ wlu.ca).

\section{REFERENCES}

Benjamin, A. S., \& Bawa, S. (2004). Distractor plausibility and criterion placement in recognition. Journal of Memory \& Language, 51, 159-172.

Brown, J., Lewis, V. J., \& Monk, A. F. (1977). Memorability, word frequency and negative recognition. Quarterly Journal of Experimental Psychology, 29, 461-473.

Brown, S., \& Steyvers, M. (2005). The dynamics of experimentally induced criterion shifts. Journal of Experimental Psychology: Learning, Memory, \& Cognition, 31, 587-599.

Cameron, T. E., \& Hockley, W. E. (2000). The revelations effect for item and associative recognition: Familiarity versus recollection. Memory \& Cognition, 28, 176-183.

CARY, M., \& ReDER, L. M. (2003). A dual-process account of the listlength and strength-based mirror effects in recognition. Journal of Memory \& Language, 49, 231-248.

Chappell, M., \& Humphreys, M. S. (1994). An auto-associative neural network for sparse representations: Analysis and application to models of recognition and cued recall. Psychological Review, 101, 103-128.

Clark, S. E., \& Hori, A. (1995). List-length and overlap effects in forced-choice associative recognition. Memory \& Cognition, 23, 456-461.

Clark, S. E., Hori, A., \& Callan, D. E. (1993). Forced-choice associative recognition: Implications for global memory models. Journal of Experimental Psychology: Learning, Memory, \& Cognition, 19, 871-881.

Clark, S. E., \& Shiffrin, R. M. (1992). Cuing effects and associative information in recognition memory. Memory \& Cognition, 20, 580-598.

Cleary, A. M., Curran, T., \& Greene, R. L. (2001). Memory for detail in item versus associative recognition. Memory \& Cognition, 29, 413-423.

Criss, A. H., \& Shiffrin, R. M. (2004a). Interactions between study task, study time, and low-frequency hit rate advantage in recognition memory. Journal of Experimental Psychology: Learning, Memory, \& Cognition, 30, 778-786.

Criss, A. H., \& Shiffrin, R. M. (2004b). Pairs do not suffer interference from other types of pairs or single items in associative recognition. Memory \& Cognition, 32, 1284-1297.

Criss, A. H., \& ShIFFrIN, R. M. (2005). List discrimination and representation in associative recognition. Journal of Experimental Psychology: Learning, Memory, \& Cognition, 31, 1199-1212. 
Dennis, S., \& Humphreys, M. S. (2001). A context noise model of episodic word recognition. Psychological Review, 108, 452-478.

Diller, D. E., Nobel, P. A., \& Shiffrin, R. M. (2001). An ARC-REM model for accuracy and response time in recognition and recall. Journal of Experimental Psychology: Learning, Memory, \& Cognition, 27, 414-435.

Dobbins, I. G., \& Kroll, N. E. A. (2005). Distinctiveness and the recognition mirror effect: Evidence for an item-based criterion placement heuristic. Journal of Experimental Psychology: Learning, Memory, \& Cognition, 31, 1186-1198.

Friendly, M., Franklin, P. E., Hoffman, D., \& Rubin, D. C. (1982). The Toronto Word Pool: Norms for imagery, concreteness, orthographic variables, and grammatical usage for 1,080 words. Behavior Research Methods \& Instrumentation, 14, 375-399.

Gillund, G., \& Shiffrin, R. M. (1984). A retrieval model for both recognition and recall. Psychological Review, 91, 1-67.

GlanZer, M., \& AdAMs, J. K. (1985). The mirror effect in recognition memory. Memory \& Cognition, 13, 8-20.

Glanzer, M., \& Adams, J. K. (1990). The mirror effect in recognition memory: Data and theory. Journal of Experimental Psychology: Learning, Memory, \& Cognition, 16, 5-16.

GlanZer, M., Adams, J. K., Iverson, G. J., \& Kim, K. (1993). The regularities of recognition memory. Psychological Review, 100, 546-567.

GREenE, R. L. (1996). Mirror effect in order and associative information: The role of response strategies. Journal of Experimental Psychology: Learning, Memory, \& Cognition, 22, 687-695.

GronLund, S. D., \& RATCLIFF, R. (1989). Time course of item and associative information: Implications for global memory models. Journal of Experimental Psychology: Learning, Memory, \& Cognition, 15, 846-858.

Hirshman, E. (1995). Decision processes in recognition memory: Criterion shifts and the list-strength paradigm. Journal of Experimental Psychology: Learning, Memory, \& Cognition, 21, 302-313.

HoCKLEY, W. E. (1992). Item versus associative information: Further comparisons of forgetting rates. Journal of Experimental Psychology: Learning, Memory, \& Cognition, 18, 1321-1330.

HoCKLEY, W. E. (1994). Reflections of the mirror effect for item and associative recognition. Memory \& Cognition, 22, 713-722.

Joordens, S., \& HockLey, W. E. (2000). Recollection and familiarity through the looking glass: When old does not mirror new. Journal of Experimental Psychology: Learning, Memory, \& Cognition, 26, $1534-1555$.

Kelley, R., \& WiXTED, J. T. (2001). On the nature of associative information in recognition memory. Journal of Experimental Psychology: Learning, Memory, \& Cognition, 27, 701-722.

Macmillan, N. A., \& Creelman, C. D. (1991). Detection theory: A user's guide. Cambridge: Cambridge University Press.

Malmberg, K. J., Holden, J. E., \& Shiffrin, R. M. (2004). Modeling the effects of repetitions, similarity, and normative word frequency on judgments of frequency and recognition memory. Journal of Experimental Psychology: Learning, Memory, \& Cognition, 30, 319-331.

Malmberg, K. J., \& Xu, J. (2007). On the flexibility and the fallibility of associative memory. Memory \& Cognition, 35, 545-556.

McClelland, J. L., \& Chappell, M. (1998). Familiarity breeds differentiation: A subjective-likelihood approach to the effects of experience in recognition memory. Psychological Review, 105, 724-760.

Morrell, H. E. R., Gaitan, S., \& Wixted, J. T. (2002). On the nature of the decision axis in signal-detection-based models of recognition memory. Journal of Experimental Psychology: Learning, Memory, \& Cognition, 28, 1095-1110.

Murdock, B. B. (1982). A theory for the storage and retrieval of item and associative information. Psychological Review, 89, 609-626.

Murdock, B. B. (2003). The mirror effect and the spacing effect. Psychonomic Bulletin \& Review, 10, 570-588.

MurnANE, K., \& SHIFFrin, R. (1991). Interference and the representation of events in memory. Journal of Experimental Psychology: Learning, Memory, \& Cognition, 17, 855-874.

Ratcliff, R., Clark, S. E., \& Shiffrin, R. M. (1990). List-strength effect: I. Data and discussion. Journal of Experimental Psychology: Learning, Memory, \& Cognition, 16, 163-178.
Reder, L. M., Nhouyvanisvong, A., Schunn, C. D., Ayers, M. S., Angstadt, P., \& Hiraki, K. (2000). A mechanistic account of the mirror effect for word frequency: A computational model of remember-know judgments in a continuous recognition paradigm. Journal of Experimental Psychology: Learning, Memory, \& Cognition, 26, 294-320.

Rotello, C. M., \& Heit, E. (2000). Associative recognition: A case of recall-to-reject processing. Memory \& Cognition, 28, 907-922.

Shiffrin, R. M., \& Steyvers, M. (1997). A model for recognition memory: REM-retrieving effectively from memory. Psychonomic Bulletin \& Review, 4, 145-166.

Singer, M., Gagnon, N., \& Richards, E. (2002). Strategies of text retrieval: A criterion shift account. Canadian Journal of Experimental Psychology, 56, 41-57.

Singer, M., \& WiXTed, J. T. (2006). Effect of delay on recognition decisions: Evidence for a criterion shift. Memory \& Cognition, 34, 125-137.

Stretch, V., \& Wixted, J. T. (1998). On the difference between strength-based and frequency-based mirror effects in recognition memory. Journal of Experimental Psychology: Learning, Memory, \& Cognition, 24, 1379-1396.

Westerman, D. L. (2000). Recollection-based recognition eliminates the revelation effect in memory. Memory \& Cognition, 28, 167-175.

Xu, J., \& MalmberG, K. J. (2007). Modeling the effects of verbal and nonverbal pair strength on associative recognition. Memory \& Cognition, 35, 526-544.

Yonelinas, A. P. (1997). Recognition memory ROCs for item and associative information: The contribution of recollection and familiarity. Memory \& Cognition, 25, 747-763.

Yonelinas, A. P., Hockley, W. E., \& Murdock, B. B. (1992). Tests of the list-strength effect in recognition memory. Journal of Experimental Psychology: Learning, Memory, \& Cognition, 18, 345-355.

\section{NOTES}

1. Strength can be manipulated between lists by varying the number of presentations or the presentation rate of the study items. Both manipulations can produce differences in the average study-test lag, or retention interval, between the two list conditions. We chose to vary presentation rate between lists because this manipulation does not change the average study-test lag measured in terms of the number of intervening stimulus presentations between study and test for each list condition. This manipulation does, though, increase the average temporal study-test lag for the lists presented at a slower rate. This confound, however, works against finding between-list strength effects, since the increased retention interval in the slower rate condition can only serve to decrease the strength manipulation. Thus, the results represent a conservative estimate of the effects of the between-list manipulations of strength on recognition performance.

2. In calculating estimates of $d^{\prime}$ and $C$ for each subject in each condition, hit rates of 1 were replaced by $[1-(1 / 2 N)]$, and false alarm rates of 0 were replaced by $(1 / 2 N)$, where $N$ is the maximum number of hits and false alarms that the subject could make in that condition (Macmillan \& Creelman, 1991).

3 . We use $\eta^{2}$ to denote partial eta squared.

4. Since single words were always presented in the first half of the study list and word pairs in the second half, there was a confounding of stimulus type and list position, so that the retention interval was greater for single items than for word pairs. We did not attempt to address this confound by counterbalancing stimulus type and list position, because we wanted to try to increase the level of recognition performance for associative recognition and, more important, because the critical comparisons in Experiment 4 were between item recognition in each presentation rate condition and associative recognition in each presentation rate condition, and not between item and associative recognition.

(Manuscript received September 6, 2005; revision accepted for publication April 17, 2006.) 